\title{
Neutrophil Infiltration, Glial Reaction, and Neurological Disease in Transgenic Mice Expressing the Chemokine N51/KC in Oligodendrocytes
}

\author{
Marie Tani, ${ }^{\star}$ Maria Elena Fuentes, ${ }^{\ddagger}$ John W. Peterson, ${ }^{\star}$ Bruce D. Trapp, ${ }^{\star}$ Stephen K. Durham, ${ }^{\S}$ James K. Loy, ${ }^{\S}$ \\ Rodrigo Bravo, ${ }^{\ddagger}$ Richard M. Ransohoff, ${ }^{\star}$ and Sergio A. Lira ${ }^{\ddagger}$ \\ *Department of Neurosciences, Research Institute, Cleveland Clinic Foundation, Cleveland, Ohio 44195; ${ }^{\ddagger}$ Department of Oncology, \\ Bristol-Myers Squibb Pharmaceutical Research Institute, Princeton, New Jersey 08543; and ${ }^{\S}$ Department of Experimental Pathology, \\ Bristol-Myers Squibb Pharmaceutical Research Institute, Princeton, New Jersey 08543
}

\begin{abstract}
Chemokines (pro-inflammatory chemoattractant cytokines) are expressed in pathological conditions of the central nervous system (CNS). Previous studies suggested that the CNS is relatively resistant to leukocyte diapedesis after chemokine injection, leaving their functional role unresolved. The CNS function of $\mathrm{N51/KC}$, a neutrophil-selective chemokine, was addressed by expressing N51/KC under control of the myelin basic protein (MBP) promoter in transgenic (tg) mice (MBPN51/KC mice). CNS-specific N51/KC expression produced remarkable neutrophil infiltration into perivascular, meningeal, and parenchymal sites, demonstrating that this chemokine exerts the multiple functions in vivo required to recruit leukocytes into the CNS. MBP-N51/KC mice represent an incisive model for the molecular dissection of neutrophil entry into the CNS. Unexpectedly, MBP-N51/KC mice developed a neurological syndrome of pronounced postural instability and rigidity at high frequency beginning at 40 days of age, well after peak chemokine expression. 68/182 mice in one tg line were found dead before one year of age, with prominent neurological symptoms premortem in 26 (38\%). Florid microglial activation and blood-brain barrier disruption without dysmyelination were the major neuropathological alterations. Late-onset neurological symptoms in MBP-N51/KC mice may indicate unanticipated consequences of CNS chemokine expression. (J. Clin. Invest. 1996. 98:529-539.) Key words: chemotactic factors - transgenic mice - cytokines • central nervous system diseases $\bullet$ leukocyte trafficking
\end{abstract}

\section{Introduction}

The central nervous system (CNS) ${ }^{1}$ lacks fully developed lym-

Address correspondence to Dr. Sergio A. Lira, Bristol-Myers Squibb Pharmaceutical Research Institute, Princeton, NJ 08543. Phone: 609252-5681; FAX: 609-252-6051; E-mail: lira@bms.com

Received for publication 26 January 1996 and accepted in revised form 24 April 1996.

1. Abbreviations used in this paper: $\mathrm{BBB}$, blood-brain barrier; CINC, cytokine-induced neutrophil chemoattractant; CLA, common leukocyte antigen; CNS, central nervous system; EAE, experimental autoimmune encephalomyelitis; MIP: macrophage inflammatory protein; GFAP, glial fibrillary acidic protein; $H \& E$, hematoxylin and eosin; ICAM, intercellular adhesion molecule; MBP, myelin basic protein; PLP, myelin proteolipid protein; tg, transgenic.

J. Clin. Invest.

(C) The American Society for Clinical Investigation, Inc.

0021-9738/96/07/0529/11 \$2.00

Volume 98, Number 2, July 1996, 529-539 phoid tissue and is isolated from the immune system by the blood brain barrier (BBB) (reviewed in references 1-4). These circumstances require an efficient means of recruiting inflammatory cells into the CNS to respond to pathogens and other noxious stimuli $(5,6)$. The precise molecular determinants of CNS leukocyte entry are unknown. The general mechanism of inflammatory cell recuitment is likely to be relevant to the pathogenesis of diverse CNS disorders such as brain trauma, cerebral infarction, multiple sclerosis (MS) and AIDS-dementia complex.

Leukocyte extravasation is a feature of diverse processes including inflammation, lymphocyte recirculation, and developmental organ colonization with leukocytes $(7,8)$. The events that govern leukocyte extravasation are in large measure conserved among these processes, and involve sequential interactions between leukocyte and endothelium via ligand-receptor pairs. Three classes of interacting molecules have been identified: selectin-carbohydrate, chemoattractant-receptor, and integrin-immunoglobulin (Ig) superfamily member $(7,8)$. Selectin-carbohydrate interactions initiate leukocyte rolling along the vessel wall. Stronger adhesion is mediated by activated leukocyte integrins and Ig superfamily members on endothelial cells.

Among the chemoattractants, chemokines, a novel family of chemoattractant cytokines (9) have been identified as important factors in leukocyte migration during inflammation [reviewed in (7, 10-19). Chemokines are small, inducible proteins made by a wide variety of cell types, which stimulate directional migration of specific target cells in vitro. They also play a role in enhancing leukocyte-endothelial cell interactions. Based on genetic, structural and functional considerations, chemokines are divided into $\alpha$ - and $\beta$-chemokine subfamilies; $\alpha$-chemokines act primarily on neutrophils, while $\beta$-chemokines are relatively specific for monocytes and lymphocytes. Selective chemokine expression may thus be a general mechanism for determining the subpopulation of leukocytes which enter tissue sites of inflammation.

$\mathrm{KC}$ (also designated N51 in the murine system and termed $\mathrm{N} 51 / \mathrm{KC}$ in this manuscript) is a rodent $\alpha$-chemokine related to the human chemokine interleukin-8 (IL-8) (20-26). N51/KC stimulates chemotaxis specifically of neutrophils, which exit rapidly from the circulation to provide the first line of cellular defense against invading pathogens. Originally identified as a transcript induced in mitogen-stimulated fibroblasts, N51/KC has high homology to the human melanocyte growth-stimulatory activity/gro proteins. When expressed in thymus or skin of transgenic mice, N51/KC mediated tissue-specific infiltration by mature neutrophils (27). Intratracheal instillation of recombinant $\mathrm{N} 51 / \mathrm{KC}$ caused neutrophil migration into rat lungs (26). N51/KC and/or IL-8 expression has been demonstrated in pathologic conditions of lung, kidney, skin, liver and CNS, consistent with the notion that chemokines are general inflam- 
matory mediators $(14,15,18,21,28-34)$. An N51/KC receptor has been identified as a mouse homolog of the human IL-8 B receptor (35-38).

In the CNS, neutrophils limit acute infections $(39,40)$. Neutrophils are also found in noninfectious conditions such as ischemia and inflammatory demyelinating syndromes such as acute hemorrhagic leukoencephalitis and the animal model experimental autoimmune encephalomyelitis (EAE) (41). Additionally, neutrophils are found in the cerebrospinal fluid in association with hemorrhage, tumor and MS $(42,43)$. Neutrophils are potent mediators of the acute inflammatory response and may promote tissue injury in these noninfectious CNS disorders.

Chemokines have been detected in a number of CNS pathological conditions such as ischemia, EAE, trauma, and bacterial meningitis, but their role in the pathogenesis and maintenance of these processes remains to be fully clarified (44-51). Recent intriguing results indicate that neutralizing antibodies to chemokines can prevent $\mathrm{T}$ cell-mediated transfer of autoimmune CNS disease (52). Further, transgenic expression of monocyte chemoattractant protein-1 (MCP-1) in the CNS of mice induced extravasation of monocytes into the perivascular space (53). Few functional studies of neutrophil chemokine activity in the CNS have been reported. Intrathecal injection of monocyte inflammatory protein (MIP)-1 caused neutrophilic meningitis and brain edema (48). Intraparenchymal injection of the chemokine IL-8 resulted in neutrophil margination within vessels but minimal extravasation, and no infiltration into the parenchyma (54). These results suggested that the CNS could be highly resistant to chemokine-driven neutrophil extravasation or infiltration. To study the function of N51/KC in the CNS, we established transgenic mice (MBP-N51/KC mice) expressing $\mathrm{N} 51 / \mathrm{KC}$ under control of $1.9 \mathrm{~kb}$ of the MBP promoter, which has been shown to drive transgene activity uniquely in oligodendrocytes, the myelin-forming cells of the CNS (55).

\section{Methods}

$M B P-N 51 / K C$ transgene construction. The transgene (Fig. $1 A$ ) was constructed by cloning N51/KC cDNA ( +2 to $+410 \mathrm{bp})$ into the XbaI-BamHI site of the plasmid pMßP, a gift from Dr. R.A. Lazzarini (Mt. Sinai Medical Center, New York, NY). The pMßP contains $1.9 \mathrm{~kb}$ of the MBP proximal promoter and enhancer which drives oligodendrocyte-specific expression in a pattern similar to endogenous MBP (55). This plasmid provided splice and polyadenylation signals from proteolipid protein (PLP) gene including part of exon 6 , intron 6 , and exon 7 . The transgene was isolated from the vector by NotI digestion followed by gel purification using a Quiaex kit (Qiagen Inc., Chatsworth, CA).

Generation of transgenic mice. The isolated transgene was microinjected into eggs of [C57BL/6J $\times$ DBA/2]F1 mice (Jackson Laboratories, Bar Harbor, ME) according to standard methodology, as previously described (27). Microinjected eggs were transferred into oviducts of ICR (Sprague-Dawley) foster mothers according to published procedures (27). Animals were kept in pathogen-free conditions. At $10 \mathrm{~d}$ of age, tail DNA was analyzed for the presence of transgene by polymerase chain reaction (PCR) using the following primers: 5'-AGAAGACCCCACAGCAGC-3' and 5'-GTGAATGAGTAGCAGCAGGT-3' that amplify a 198-bp segment of the transgene. $\beta$-thyroid stimulating hormone primers, previously described, served as an internal control for this reaction (27). PCR conditions were: $95^{\circ} \mathrm{C}$ for $60 \mathrm{~s} ; 55^{\circ} \mathrm{C}$ for $90 \mathrm{~s} ; 72^{\circ} \mathrm{C}$ for $60 \mathrm{~s}$ for 30 cycles (27). Transgenic lines heterozygous for the transgene were established.

RNA analysis. RNA was extracted from tissues using RNAzol following manufacturer's instructions (Cinna/Biotecx, Houston, TX).
Total RNA $(10 \mu \mathrm{g})$ was denatured and blotted onto Hybond-N membrane (Amersham Corp., Arlington Hts., IL). A 312-bp fragment of the murine N51/KC cDNA was radiolabeled using a random-priming DNA labeling kit (Amersham) and was used as a probe in dot-blot experiments (23).

Western blot. Brains from transgenic and control mice were homogenized in $2 \mathrm{ml}$ of $10 \mathrm{mM}$ Tris- $\mathrm{HCl} \mathrm{pH} 7.4,5 \mathrm{mM}$ EDTA, $0.2 \mathrm{M}$ $\mathrm{NaCl}, 1 \%$ Triton $\mathrm{X}-100$ and $1 \mathrm{mM}$ phenylmethylsulfonylfluoride (Sigma Chemical Co., St. Louis, MO). After centrifugation, protein content of the supernatant was determined and $75 \mu \mathrm{g}$ of total protein

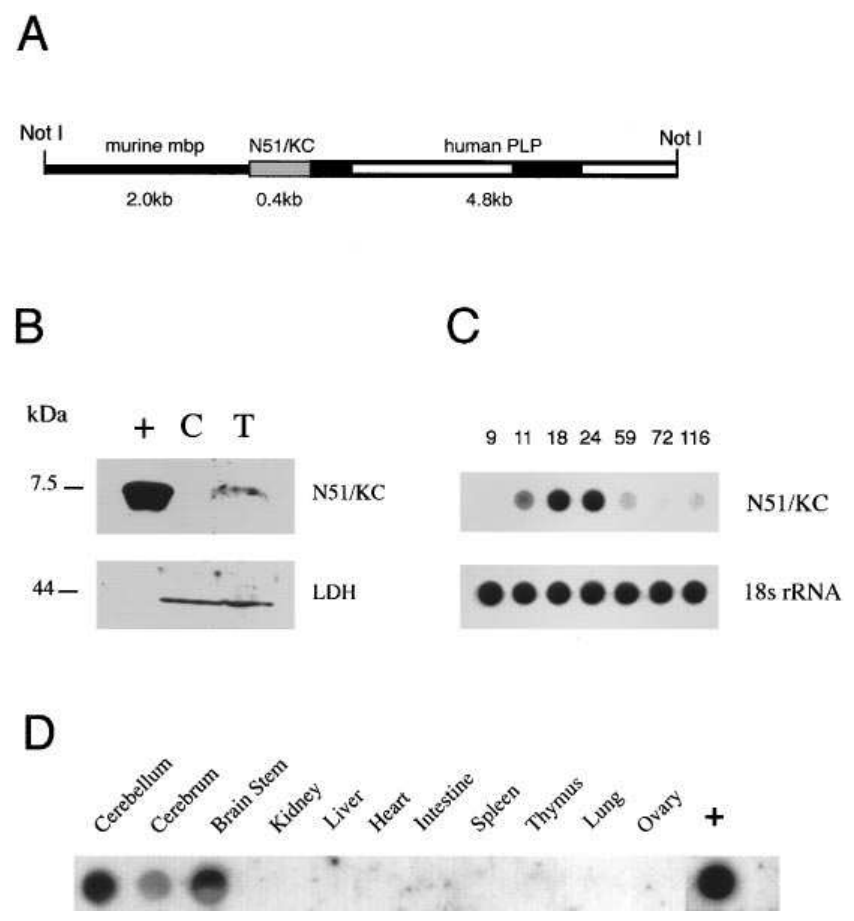

Figure 1. Transgene construction and expression in MBP-N51/KC mice. (A) Diagram of the MBP-N51/KC transgene. The murine MBP regulatory element is shown as a thin black line. N51/KC cDNA is shown in gray. Human PLP exons 6 and 7 are shown as thick black lines with the intervening PLP intron 6 represented by an open line. Flanking NotI restriction endonuclease sites used to release the transgene from the plasmid are shown. (B) Western blot analysis of N51/ $\mathrm{KC}$ in the CNS of transgenic mice showed that N51/KC was present in brains of tg mice only. Soluble protein was prepared from brains of normal control (C) and transgenic (T) mice at age $3 \mathrm{wk}$ and subjected to Western blot analysis with polyclonal antibodies to $\mathrm{N} 51 / \mathrm{KC}$, as described in Methods. Recombinant N51/KC was co-electrophoresed as a positive control $(+)$. Migration of molecular size markers is shown at left. Antibodies to lactic dehydrogenase (LDH) were used to demonstrate equal loading of protein from control and transgenic brain samples. (C) Time course of N51/KC RNA accumulation in CNS of $\mathrm{tg}$ mice followed the previously reported pattern of endogenous MBP expression. RNA was prepared from brains of tg mice of varying ages (in days) as indicated at top. $10 \mu \mathrm{g}$ of total RNA was analyzed by high-stringency dot-blot hybridization for N51/KC transcripts as described in Methods. N51/KC mRNA was first detected at $11 \mathrm{~d}$; N51/ KC expression peaked at 18-24 d, and declined progressively thereafter to persistent low levels after 59 days. Parallel samples were analyzed for $18 \mathrm{~s}$ ribosomal RNA, to ensure equal content of hybridizable RNA in all samples, as shown at bottom. $(D)$ MBP-driven N51/ $\mathrm{KC}$ expression is limited to the CNS. At 3 wk of age, RNA was prepared from CNS tissues (cerebellum, cerebrum and brainstem) and other organs as indicated. By dot-blot hybridization, N51/KC transcripts are detected only in CNS tissues. 
per extract was separated by polyacrylamide gel electrophoresis and blotted onto Hybond ECL membrane (Amersham) using a semi-dry procedure. $\mathrm{N} 51 / \mathrm{KC}$ was detected using a monospecific antibody, as previously described (27).

Histological and immunohistochemical examination of CNS tissues. After cardiac perfusion of mice with $4 \%$ paraformaldehyde solution in $0.1 \mathrm{M}$ phosphate buffer, brains and spinal cords were dissected and immersed overnight in cryoprotection solution $(20 \%$ glycerol, $0.08 \mathrm{M}$ Sorenson's buffer, $\mathrm{pH}$ 7.6). 30- $\mu \mathrm{m}$-thick coronal sections of the brain and transverse sections of the spinal cord were cut on a sliding microtome (Leica, Deerfield, IL). Tissue sections were stained with hematoxylin and eosin $(\mathrm{H} \& \mathrm{E})$, cresyl violet or immunostained as free-floating sections. For immunostaining, sections were pretreated as necessary by microwaving twice for $5 \mathrm{~min}$ each in $10 \mathrm{mM}$ sodium citrate buffer, $\mathrm{pH}$ 6.0, placed in $1 \% \mathrm{H}_{2} \mathrm{O}_{2}, 10 \%$ Triton X-100 in PBS for $30 \mathrm{~min}$; blocked with $3 \%$ normal goat or rabbit serum (Sternberger Monoclonals, Baltimore, MD) in PBS for $30 \mathrm{~min}$; incubated in primary antibody overnight at $4^{\circ} \mathrm{C}$; incubated in appropriate biotinylated secondary antibody for $30 \mathrm{~min}$; immersed in avidin-biotin-horseradish peroxidase complex diluted 1:1000 for $1 \mathrm{~h}$ (Vectastain Elite ABC Kit, Vector, Burlingame, CA $)$; stained in diaminobenzidine $(0.67 \mathrm{mg} /$ $\mathrm{ml}$, Sigma Chemical Co.), $0.01 \% \mathrm{H}_{2} \mathrm{O}_{2}$ in PBS; enhanced with $0.04 \%$ osmium tetroxide (Electron Microscopy Sciences, Fort Washington, PA) for $30 \mathrm{~s}$ and mounted in glycerol. The primary antibodies and working dilutions in PBS were as follows: rat monoclonal antimurine neutrophils (also called 7/4, 1:200), rat monoclonal anti-F4/80 $(1: 200)$ and rat monoclonal anti-murine intercellular adhesion molecule-1 (ICAM-1, 1:10,000) were obtained from Serotec (Washington, D.C.); goat anti-murine IgG (1:10,000, Vector); rat monoclonal anticommon leukocyte antigen (CLA, 1:200, Boehringer-Mannheim, Indianapolis, IN); rabbit polyclonal anti-bovine glial fibrillary acidic protein (GFAP, 1:5000; Dako, Santa Barbara, CA); rat monoclonal anti-PLP (1:200, Agmed, Bedford, MA); and mouse monoclonal anti-phosphorylated neurofilament $(1: 10,000$, Sternberger Monoclonals). Rabbit polyclonal KC antibodies $(1: 10,000)$ and recombinant bacterially produced $\mathrm{KC}$ were generously provided by Drs. Craig Gerard and Carmen Bozic (Children's Hospital Medical Center, Boston, MA) (25). For preabsorption of the KC antiserum, purified bacterially produced $\mathrm{KC}(0.04 \mathrm{mg} / \mathrm{ml})$ was incubated with a $1: 10$ dilution of the antibodies at room temperature for one hour, then diluted to final 1:10,000 for immunohistochemistry. Biotinylated secondary antibodies (Vector) were used at a dilution of 1:500.

Electron microscopy. Animals were perfused with McDowellTrump solution in $0.1 \mathrm{M}$ phosphate buffer (53). After post-fixation, tissues were dehydrated in a graded series of methanol baths and embedded in epoxy resin. 1- $\mu$ m-thick sections were cut from the epoxyembedded material, stained with toluidine blue and delineated for ultrathin sections. Ultrathin sections of brain, $\sim 60-90 \mathrm{~nm}$ thick, were mounted on copper grids, stained with uranyl acetate and lead citrate and examined with a Zeiss $10 \mathrm{C}$ transmission electron microscope.

\section{Results}

Generation of transgenic mice and determination of transgene expression. After microinjection experiments, we determined the presence of transgene by PCR analysis of tail DNA. Western blot showed the CNS of transgenic mice contained N51/ $\mathrm{KC}$ (Fig. $1 \mathrm{~B}$ ). Transgene mRNA expression followed the developmentally-regulated pattern of endogenous MBP, peaking at 2-3 wk of age, then declining to low levels characteristically seen in adult brain (55) (Fig. $1 C$ ). Dot-blot analysis of N51/KC mRNA levels in kidney, liver, heart, intestine, spleen, thymus, lung, cerebellum, cerebrum and brain stem indicated that transgene expression was limited to the CNS, consistent with previous studies of gene expression directed by the $1.9-\mathrm{kb}$ MBP promoter (55) (Fig. $1 \mathrm{D}$ ). Three of three founder mice and 2 of 6 transgenic lines had abundant neutrophil infiltration in the CNS at $3 \mathrm{wk}$ of age. Infiltrates were readily detected at all levels of the neuraxis, including cerebrum, brain stem, and spinal cord (not shown).

Progressive neurological dysfunction in $\mathrm{MBP}-\mathrm{N} 51 / \mathrm{KC}$ tg mice. MBP-N51/KC tg mice did not exhibit detectable behavioral phenotype at 3 weeks, the time of maximal chemokine expression and gross, focal CNS neutrophilia (Figs. 2 and $3 A$ ). Thereafter, however, tg mice of the high-expressor line 17 exhibited grossly decreased life span. Of 182 mice from line 17, $68(37 \%)$ were found dead at ages $<350$ d. 22 of these 68 mice (32\%) died at age $<100 \mathrm{~d} ; 17$ mice $(25 \%)$ died between 100 and $150 \mathrm{~d}, 21$ mice (31\%) died between 151-250 d and 8 mice (12\%) died between 251-350 d. 26 (38\%) of 68 mice later found dead exhibited a syndrome of progressive neurological dysfunction during the premortem period. Initial signs of neurological dysfunction invariably appeared in affected mice after $40 \mathrm{~d}$, well beyond the peak of chemokine expression, and consisted of slowing of the righting reflex. With time, circling behavior and clumsiness became evident in the absence of prominent weakness. Spontaneous fine motor behaviors of the forepaws were unimpaired, arguing against pyramidal tract dysfunction. Affected mice subsequently developed increased rigidity of hindlimbs and tail and profound truncal instability with striking in-

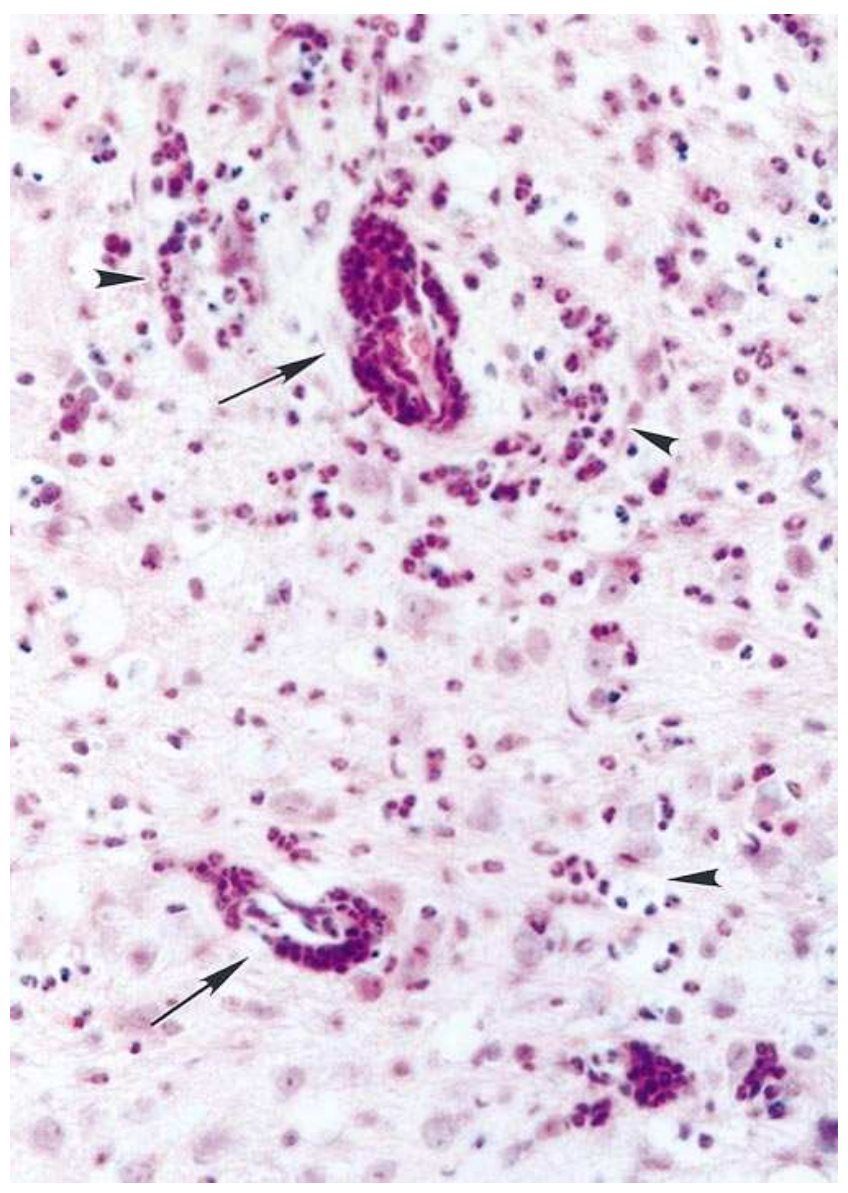

Figure 2. Neutrophil infiltration of the CNS of N51/KC tg mice is evident at 3 wk of age. Dense perivascular (arrows) and parenchymal (arrowheads) infiltration by mature neutrophils displaying characteristic lobulated nuclei and eosinophilic cytoplasm is evident in this section of brain $(\mathrm{H} \& \mathrm{E} ; \times 360)$. 

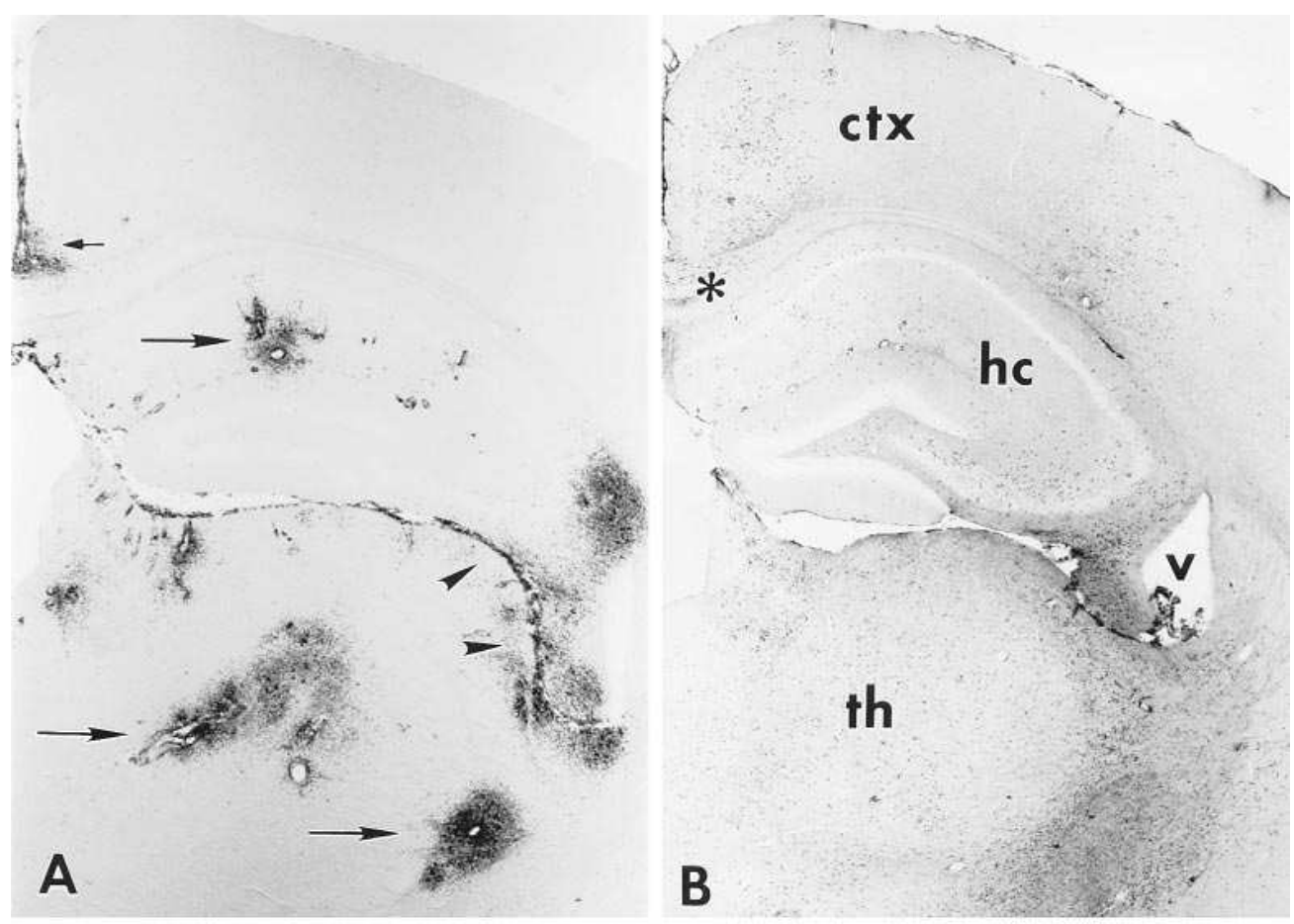

Figure 3. Immunohistochemical detection of neutrophils and $\mathrm{N} 51 / \mathrm{KC}$ in transgenic mice. Coronal sections of brain were immunostained using $7 / 4$, an anti-murine neutrophil antibody or polyclonal anti-N51/KC antibodies as described in Methods. (A) 7/4 immunostaining in a 22d-old MBP-N51/KC mouse brain revealed intense, focal perivascular (large arrows), periventricular (arrowheads) and meningeal (small arrow) neutrophilic infiltrates. $\times 24$. (B) In older transgenic mice, neutrophil infiltration in the CNS became diffuse, as in this 179-d-old mouse. Widespread parenchymal neutrophil infiltration is evident in the cortex (ctx), hippocampus $(h c)$, thalamus $(t h)$, as well as in the corpus callosum (*), a major white matter tract, and periventricular white matter $(v$ indicates ventricle). $\times 24$. (C) In a 22-d-old tg mouse, cytoplasmic N51/KC immunostaining is found in myelinating areas of the brain such as the corpus callosum shown here (and located by the asterisk in $B$ ), consistent with the production of $\mathrm{N} 51 / \mathrm{KC}$ by oligodendrocytes. Note the round, refractile neutrophils near the interhemispheric fissure at the upper right. $\times 90$. (D) Preabsorption of N51/ $\mathrm{KC}$ antiserum with recombinant $\mathrm{KC}$ before immunostaining, as described in Methods, abolished cellular reactivity, as in this region of corpus callosum, indicating the specificity of the polyclonal antiserum. $\times 90$.

ability to maintain upright posture with the head extended (as towards water source). The animals died in an emaciated state, probably because of inability to reach food and water, as extraneural pathologic abnormalities detected at necropsy were limited to wasting and occasional mild myeloid hyperplasia.

The median duration of unequivocal symptoms before death was $9 \mathrm{~d}$ (range 2-154) with a mean of $34 \pm 48 \mathrm{~d}$ (standard deviation). Mice that died before $100 \mathrm{~d}$ were less likely (affected mice $=4 / 22 ; 18 \%$ ) to exhibit symptoms than those dying between $100-250 \mathrm{~d}(14 / 38 ; 38 \%)$. Mice dying after $250 \mathrm{~d}$ were highly likely to evidence frank neurological impairment (7/8; 87.5\%). 114 mice from line 17 remain alive, 15 of which $(13 \%)$ are $>350 \mathrm{~d}$ of age, while $54(47 \%)$ are $250-350 \mathrm{~d} .13$ $(11 \%)$ surviving mice have recently developed typical neurological impairment; only 1 of 13 remains alive with neurological symptoms after more than $8 \mathrm{wk}$.

Neuropathological analysis of MBP-N51/KC tg mice. Serial sections of CNS tissues from two transgenic lines, designated line 17 and line 62, were examined and compared with samples from non-tg mice of the background strain. Line 62 had modest neutrophil infiltration and similar but milder histological changes compared to line 17 , correlating with lower transgene expression. Detailed studies were focused on line 17, which had the most pronounced changes. CNS tissues of line 17 mice were subjected to detailed histological and immunohistochemical examination at ages $3 \mathrm{wk}(n=3), 41 \mathrm{~d}(n=1), 68 \mathrm{~d}(n=1)$, $101 \mathrm{~d}(n=1), 122 \mathrm{~d}(n=1), 137 \mathrm{~d}(n=2)$ and $179 \mathrm{~d}(n=2)$. All mice examined after the first three weeks had demonstrated neurological symptoms before sacrifice.

Neutrophil infiltration of CNS tissues. In MBP-N51/KC $\mathrm{tg}$ mice, H\&E staining at three weeks of age revealed sheets of mature neutrophils in the CNS parenchyma (Fig. 2). Immunostaining with murine neutrophil-specific monoclonal antibody $7 / 4$ confirmed the presence of neutrophils lining the ventricles, blood vessels and leptomeninges, and focal granulocytic infiltrates throughout the CNS parenchyma (Fig. $3 A$ ). Compara- 
ble CNS tissues from the nontransgenic background strain contained rare neutrophils within blood vessels (data not shown). In brains of older tg mice (41-179 d), a progressively more diffuse and widespread pattern of infiltration by mature neutrophils was revealed by $7 / 4$ staining (Fig. $3 \mathrm{~B}$ ). Gross and microscopic examination of tg brains showed no signs of tissue edema or hyperemia at any age. $\mathrm{N} 51 / \mathrm{KC}$, detected by immunohistochemistry as punctate cytoplasmic staining, was concentrated in white matter containing myelinated axons at all ages examined, consistent with production of $\mathrm{N} 51 / \mathrm{KC}$ by oligodendrocytes (Fig. $3 \mathrm{C}$ ). Specificity of this immunostaining was documented by abolishing reactivity, through preabsorption of the antisera with recombinant N51/KC (Fig. 3D).

Vascular alterations. In 3-wk-old mice, medium-sized veins demonstrated exuberant cuffing with neutrophils within the perivascular space or infiltrating into the parenchyma (Figs. 2 and $3 A$ ). It was of interest to evaluate blood brain barrier (BBB) integrity, which was analyzed by staining for mouse $\mathrm{IgG}$, a marker of extravasated serum proteins. In normal mouse brain IgG immunostaining was limited to areas which have no BBB, such as the choroid plexus and hypothalamus (data not shown). In tg mice, BBB breakdown was observed at sites of neutrophil infiltration into parenchyma (Fig. $4 A$ ). High-magnification view of vascular sites of neutrophil extravasation showed a grossly expanded perivascular space (Fig. $4 \mathrm{~B}$ ). To characterize vascular pathology further, endothelial cells were visualized by immunostaining for ICAM-1, the vascular adhesion molecule which binds CD11b/CD18 on neutrophils. ICAM-1 was highly expressed on virtually all vessels in the CNS of both background strain and tg mice, and the perivascular space was again shown to be distended in tg mice (Fig. 4, $C-D$ ). In normal mouse brain, vessels were circumscribed by an intact barrier of astrocytic footprocesses, which aid in the maintenance of the BBB (Fig. 4 E, arrows). In tg brain, where invading leukocytes remained confined in the perivascular space, this girdle of astrocyte footprocesses was maintained (Fig. 4 F, arrows). Near adjacent vessels in these tg brains, neutrophil entry into parenchyma could be seen; at these sites, vessels demonstrated a disrupted astrocytic barrier and surrounding astrocyte activation (Fig. 4 F, arrowheads).

Fate of infiltrating neutrophils. It was of interest to evaluate the fate of neutrophils that infiltrated the CNS of MBP-N51/

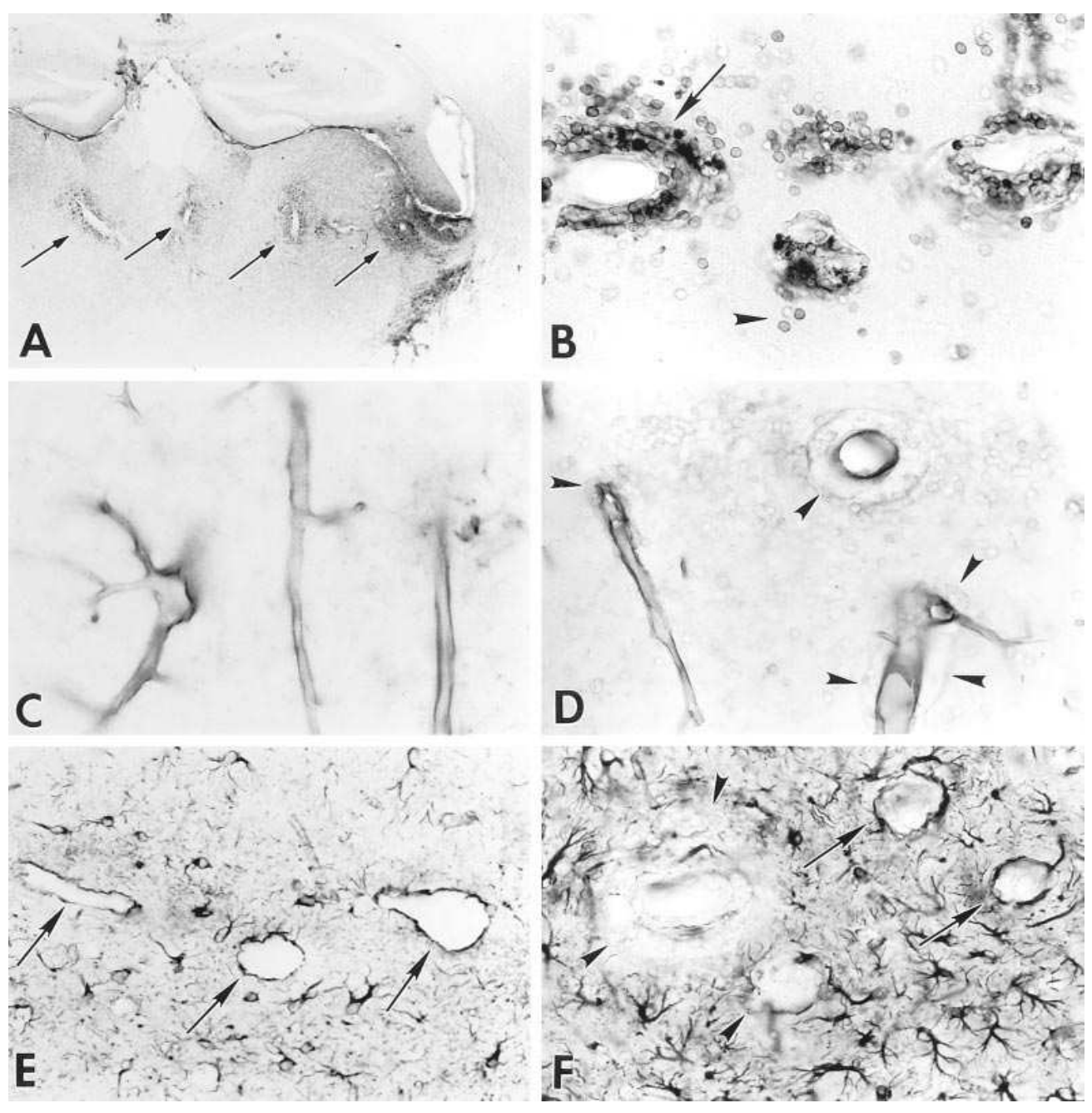

Figure 4. Vascular alterations associated with neutrophil infiltrates in brains of 3-wk-old MBP-N51/KC tg mice. Coronal brain sections were immunostained as described in Methods. (A) Focal blood-brain barrier disruption in brains of MBP$\mathrm{N} 51 / \mathrm{KC}$ tg mice was revealed by immunostaining with antibodies to murine $\mathrm{IgG}$, a serum protein normally excluded from entering the brain by the BBB. In this serial section of the same brain shown in Fig. 3 A, IgG leak into the CNS parenchyma is evident around several vessels harboring perivascular neutrophil aggregates (arrows). $\times 16$. (B) 7/4 immunostaining reveals dense perivascular neutrophil aggregates with consequent gross expansion of perivascular spaces (arrow) as well as infiltration into the surrounding parenchyma (arrowhead) $(256 \times)$. (C) Vascular endothelia of the brain of non-tg background strain mice were heavily stained with antibodies to ICAM-1. $\times 256$. (D) ICAM-1 immunostaining in tg mice was similarly intense in vascular endothelial cells, revealing the vascular lumena and widened perivascular space choked with neutrophils (arrowheads). $\times 256$. (E) Astrocytic footprocesses normally sur-

round cerebral vessels and aid in maintenance of the BBB, as shown by GFAP immunostaining in this non-tg mouse brain (arrows). Quiescent astrocytes in surrounding parenchyma are also stained. $\times 256 .(F)$ In Tg mice, astrocytic footprocesses appear to confine infiltrating cells to the perivascular space (arrows). At sites of neutrophil infiltration of the brain parenchyma, vessels have lost this barrier of astrocytic footprocesses (arrowheads). Enlarged processes of reactive astrocytes are also evident in surrounding parenchyma. $\times 256$. 
$\mathrm{KC}$ mice. In brains of tg mice of all ages, neutrophils with degradative changes including eosinophilic cytoplasm, nuclear pyknosis and karyolysis were readily detected (data not shown). Ultrastructurally, neutrophils with condensed nuclear chromatin, abundant lysosomal, and glycogen granules in the cytoplasm and intact cell membrane were observed, consistent with apoptotic cell death (Fig. $5 A$ ). Similar cells were found engulfed by macrophages, suggesting the neutrophils remained quiescent until undergoing apoptosis and phagocytosis (Fig. 5 $B)$. These apoptotic cells corresponded with pyknotic forms that were heavily immunoreactive with antibodies to CLA (an isoform of CD45 that serves as a panleukocyte marker (Fig. 6, $E$ and $G$ ). Apoptotic neutrophils could be detected in close proximity to morphologically intact neurons. No ultrastructural indication of neutrophil degranulation was observed (Fig. $5 \mathrm{~A}$ ). These observations suggested that neutrophils in CNS tissues of $\mathrm{tg}$ mice remained quiescent. Attempts to activate the neutrophils in asymptomatic tg mice at $3 \mathrm{wk}$ of age with intraperitoneal lipopolysaccharide $(n=6)$ had no discernible effect.

Infiltrating neutrophils incite local glial activation. The microglial reaction to this tg-induced neutrophil infiltration was analyzed by comparative immunostaining for $7 / 4$ (which labels neutrophils) CLA (which labels neutrophils and weakly detects hematogenous macrophages and microglia) and F4/80 (expressed only by macrophages and microglia). These analyses revealed focal microglial reaction in regions of neutrophil infiltration in younger mice (compare Figs. 3, $A$ and $B$; see also Fig. 6, $D$ and $E$ ). With advancing age, microglial activation was progressively more widespread and intense throughout the CNS, as neutrophil infiltration became diffuse (Figs. 3, $B$ and $6, C, F$ and $G$ ). In older mice, reactive microglia were grossly enlarged with remarkable process extension (Fig. $6, F$ and $G$ ).
Close apposition between pyknotic neutrophils and activated microglia was observed, using CLA immunostaining that labeled both cell populations (Fig. $6 G$ ). Many macrophage/microglia appeared to be phagocytizing apoptotic neutrophils (Fig. 6, $D-G$ ). By ultrastructural analysis, macrophages contained remnants of phagocytized neutrophils, as indicated by angular crystalloid material (Fig. $5 \mathrm{~B}$ ). These profiles resembled those observed previously in $\operatorname{tg}$ mice with thymus-specific N51/KC expression (27).

Astrocytic reaction was detected by immunoreactivity for GFAP, a specific astrocyte marker $(56,57)$. Reactive astrocytosis in 3-wk-old mice was focal, and confined to regions of intense neutrophil infiltration (Fig. 7 B). In older mice with neurological dysfunction and widespread microglial activation, the astrocytic reaction was diffuse and remarkably intense (Fig. $7 C$ ).

Myelination in tg mice. Neurological dysfunction in MBP$\mathrm{N} 51 / \mathrm{KC}$ tg mice could potentially be explained by dysmyelination, caused by programming oligodendroglia to express exogenous gene products. Such dysmyelination has complicated the interpretation of previous experiments in which the MBP promoter was used to direct the expression of cell-surface transgene products $(58,59)$. Immunostaining with antibodies to myelin PLP revealed intact myelin sheaths (Fig. $8 A$ ). Rarely, mild mechanical displacement of myelinated fibers was detected, in foci of massive neutrophil infiltration in younger MBP-N51/KC tg mice (Fig. 8 B). Immunostaining of phosphorylated neurofilaments indicated the structural integrity of myelinated nerve fibers in these regions of heavy neutrophil infiltration (data not shown). In older mice, PLP immunostaining revealed morphologically normal myelin (data not shown), despite chronic neutrophil infiltration and pronounced microglial and astrocytic reaction.
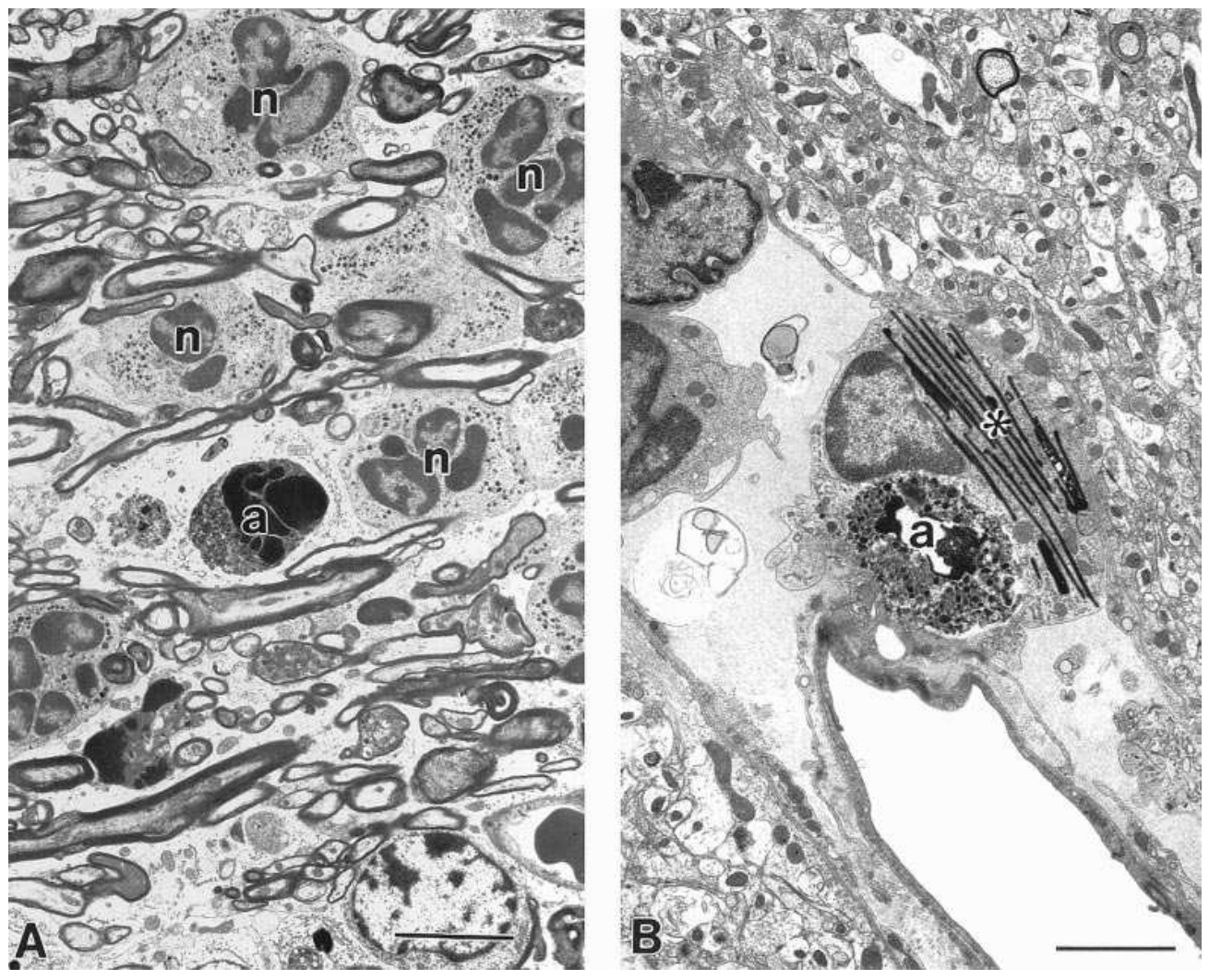

Figure 5. Ultrastructural evaluation of infiltrating neutrophils in MBP-N51/KC tg brain. (A) Several intact, mature neutrophils (n) containing large amounts of glycogen and an apoptotic neutrophil (a) with condensed chromatin, intact cytoplasmic granules and plasma membrane are dispersed among myelinated fibers. Bar, $5 \mu \mathrm{m}$. (B) A perivascular macrophage contains an apoptotic neutrophil $(a)$ and angular, crystalloid material $(*)$ which is probably remnants of phagocytized neutrophils. The surrounding neuropil appears normal. Bar, $5 \mu \mathrm{m}$. 


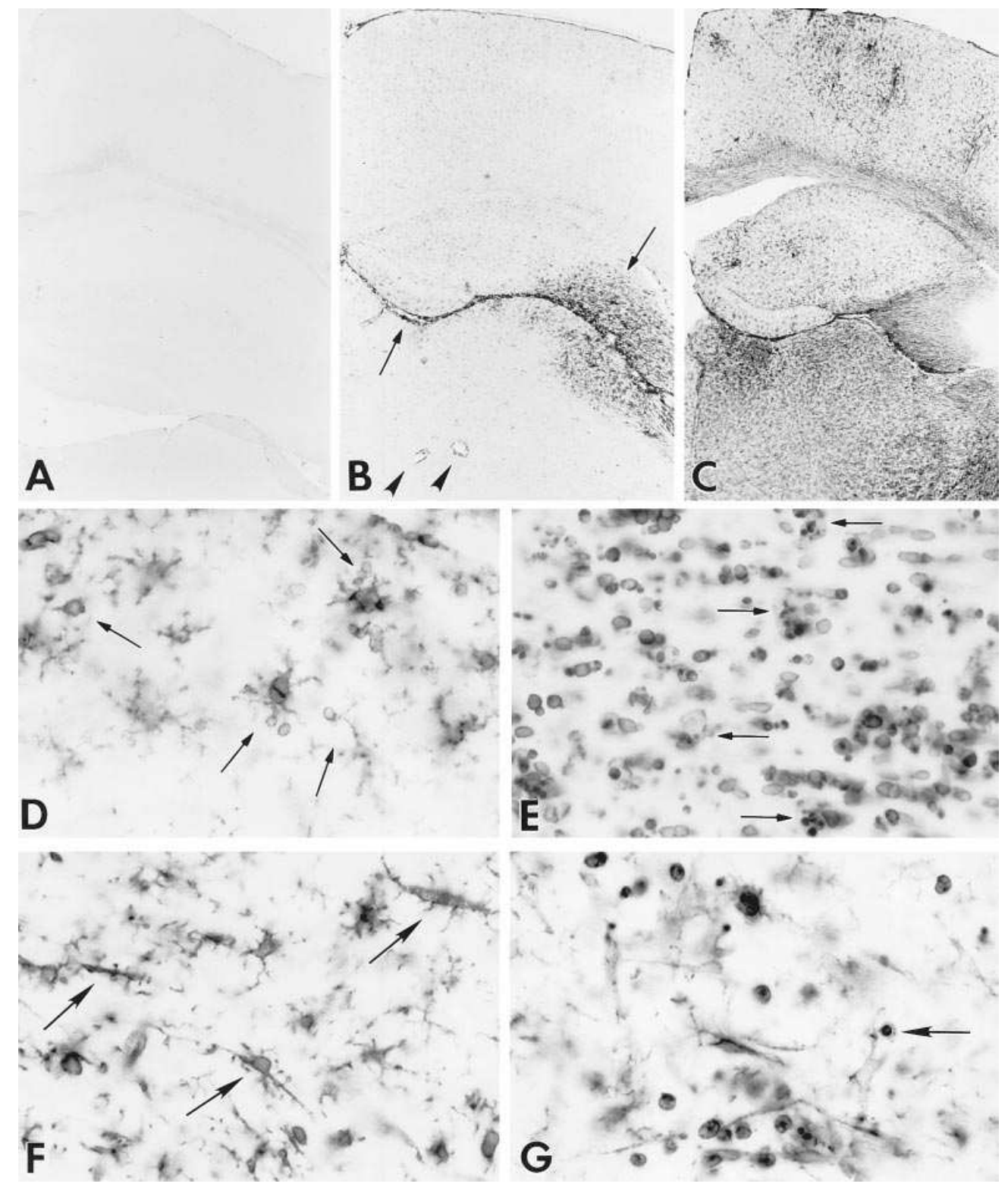

Figure 6. Microglial reaction in brains of MBP-N51/KC tg mice. Coronal brain sections were immunostained with F4/80, which labels macrophages and microglia, or CLA, a panleukocyte marker, as described in Methods. (A) In brain of backgroundstrain mouse at $70 \mathrm{~d}$, quiescent resident microglia do not stain with F4/80 antibody. $\times 26$. (B)

F4/80 staining in a 19-d tg mouse shows marked focal macrophage and microglial reactivity in areas of heavy neutrophil infiltration, particularly in periventricular (arrows) and perivascular (arrowheads) locations. $\times 26$. (C) In older tg mice, macrophage/microglial activation became widespread and increasingly intense, as shown by $\mathrm{F} 4 / 80$ staining in this 101-d-old tg brain. $\times 26$. $(D)$ Higher magnification of the periventricular region of the section in Figure 5B stained with F4/80. Markedly enlarged macrophages/microglia bear multiple processes, many of which appear to have engulfed spherical objects that are apoptotic neutrophils $($ arrows). $\times 345$. (E) In this periventricular region of a 19-d tg mouse, CLA antibody stains neutrophils intensely as dark, round cells and macrophages/microglia weakly. Large, weakly stained macrophages/microglia appear to have engulfed mutliple small, densely stained apoptotic neutrophils (arrows). $\times 345$. $(F)$ In the 101-d tg mouse shown in Fig. 5 , higher magnification of $\mathrm{F} 4 / 80$ staining reveals gigantic reactive macrophages/

microglia, many with a bizarre, elongated form (arrows). $\times 345$. $(G)$ CLA immunostaining in a 101-d tg mouse shows scattered round neutrophils and weaker-staining, elongated macrophages/microglia, one of which appears to be phagocytizing an apoptotic neutrophil (arrow). $\times 345$.

Neurons in tg mice. The motor cortex, basal ganglia, cerebellum, and spinal cord were carefully examined by light microscopy, given the prominent motor abnormalities that were observed in tg mice. H\&E stain of CNS tissues revealed normal distribution and appearance of neurons at all ages in the cerebral and cerebellar cortex, basal ganglia and spinal cord, compared to age-matched healthy controls (data not shown). Moreover, cresyl violet staining of Nissl substance, a general marker of neuronal metabolic activity, revealed a normal pattern of staining throughout the CNS (data not shown). Finally, there was no evidence of neuronophagia.

\section{Discussion}

Generation and analysis of MBP-N51/KC tg mice. The CNS function of a neutrophil-selective chemoattractant N51/KC was ad- dressed by constructing transgenic mice, in which chemokine expression was governed by the developmentally regulated MBP promoter and targeted to oligodendrocytes. Two striking results arose from these experiments. First, neutrophils infiltrated the $\mathrm{CNS}$ of these tg mice in perivascular, meningeal, and parenchymal compartments; these neutrophils remained quiescent until undergoing apoptosis and phagocytosis by macrophages $/ \mathrm{mi}-$ croglia. The second major finding of these studies was that neurological symptoms occurred with high frequency in highexpressor tg mice. The syndrome of pronounced ataxia led to terminal wasting, with greatly decreased life span in affected animals.

N51/KC functions as a neutrophil chemoattractant in the CNS. At three weeks of age, around the peak of transgene mRNA expression, brains of MBP-N51/KC tg mice contained sheets of mature neutrophils around ventricles, meninges, and blood vessels, from which neutrophils had infiltrated into the 

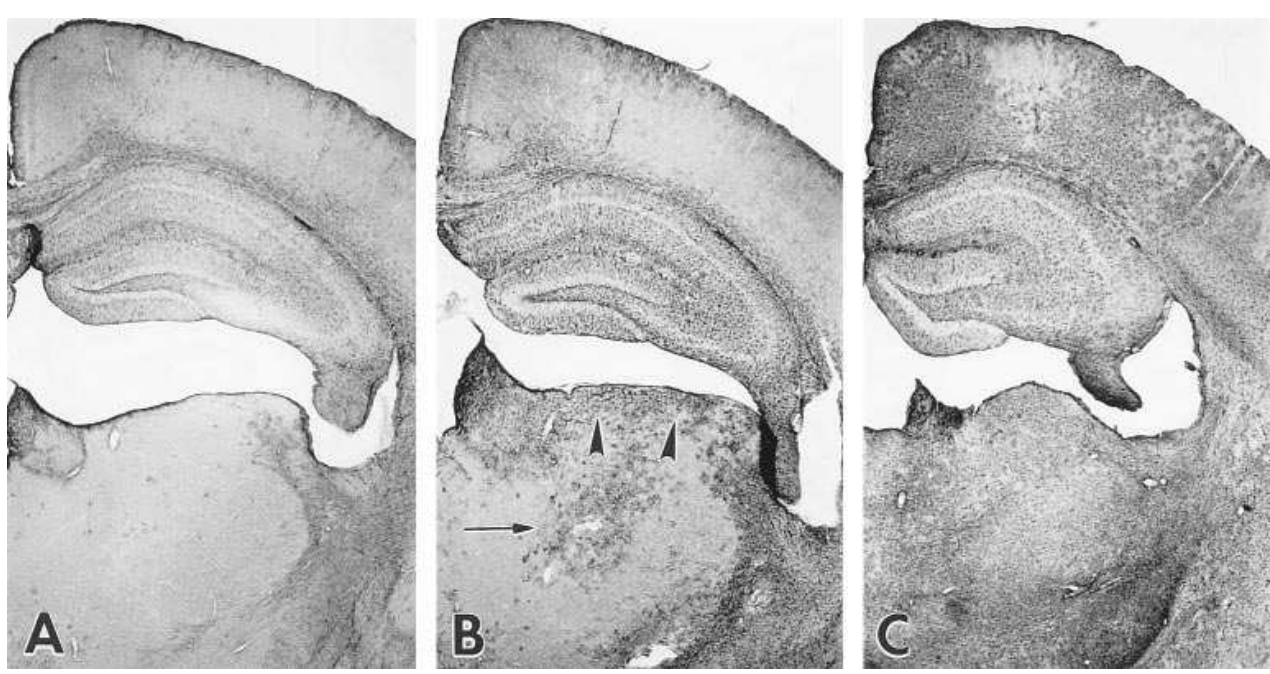

Figure 7. Reactive astrocytosis in MBP-N51/KC tg mice. Coronal brain sections were immunostained with antibodies to GFAP, a specific marker of astrocytes, as described in Methods. (A) Pattern of GFAP immunoreactivity in a normal, 70-d-old non-tg mouse. $\times 16$. (B) In a 19-d tg mouse, focal, increased GFAP immunostaining indicates astrocyte activation in perivascular (arrow) and periventricular (arrowheads) areas which are heavily infiltrated by neutrophils (compare with Fig. $3 A$ ).

Higher magnification of this region demonstrating reactive astrocytosis is seen in Fig. $4 F$. $\times 16$. (C) In older tg mice, intense astrocyte activation is diffuse and widespread, following the pattern of neutrophil infiltration (Fig. $3 \mathrm{~B}$ ) and microglial activation (Fig. $5 \mathrm{C}$ ). $\times 16$.
CNS parenchyma (Figs. 2 and $3 A$ ). Despite robust infiltration with neutrophils, the transgenic mice appeared behaviorally normal. The absence of tissue edema, the patchy astroglial and microglial reaction and the minimal myelin and axonal disruption suggest that $\mathrm{N} 51 / \mathrm{KC}$ functions primarily as a neutrophil chemoattractant, without significant neutrophil-activating properties in this system. After migration into tissue in response to $\mathrm{N} 51 / \mathrm{KC}$, neutrophils appeared to undergo apoptosis without degranulation. These observations are consistent with in vitro studies in which recombinant $\mathrm{N} 51 / \mathrm{KC}$ caused increased integrin CD11b/CD18 expression on neutrophils but only modest increase in respiratory burst (26). In pathologic conditions other factors are likely to be necessary to activate fully the neutrophil functions of degranulation, respiratory burst, and cytokine secretion. In this regard, the related human neu- trophil chemokines IL-8 and GRO $\alpha$ do not stimulate superoxide anion production directly, but up-regulate $\mathrm{N}$-formyl peptide receptors on neutrophils and potentiate superoxide production in response to bacterial components (60).

After the early postnatal burst of MBP-promoter-driven transgene activity, a low level of N51/KC expression stimulates persistent and diffuse neutrophil migration into the CNS parenchyma. In older MBP-N51/KC mice, immunostaining for $\mathrm{N} 51 / \mathrm{KC}$ in oligodendroglia remained widespread, indicating ongoing promoter activity (data not shown). Others have reported that intradermal injection of the neutrophil chemoattractants C5a, FMLP and leukotriene B4 resulted in transient inflammatory cell influx while human IL-8 mediated persistent chemoattractant effect, suggesting that $\alpha$-chemokines may express chemoattractant potential at all stages of inflammation (61).
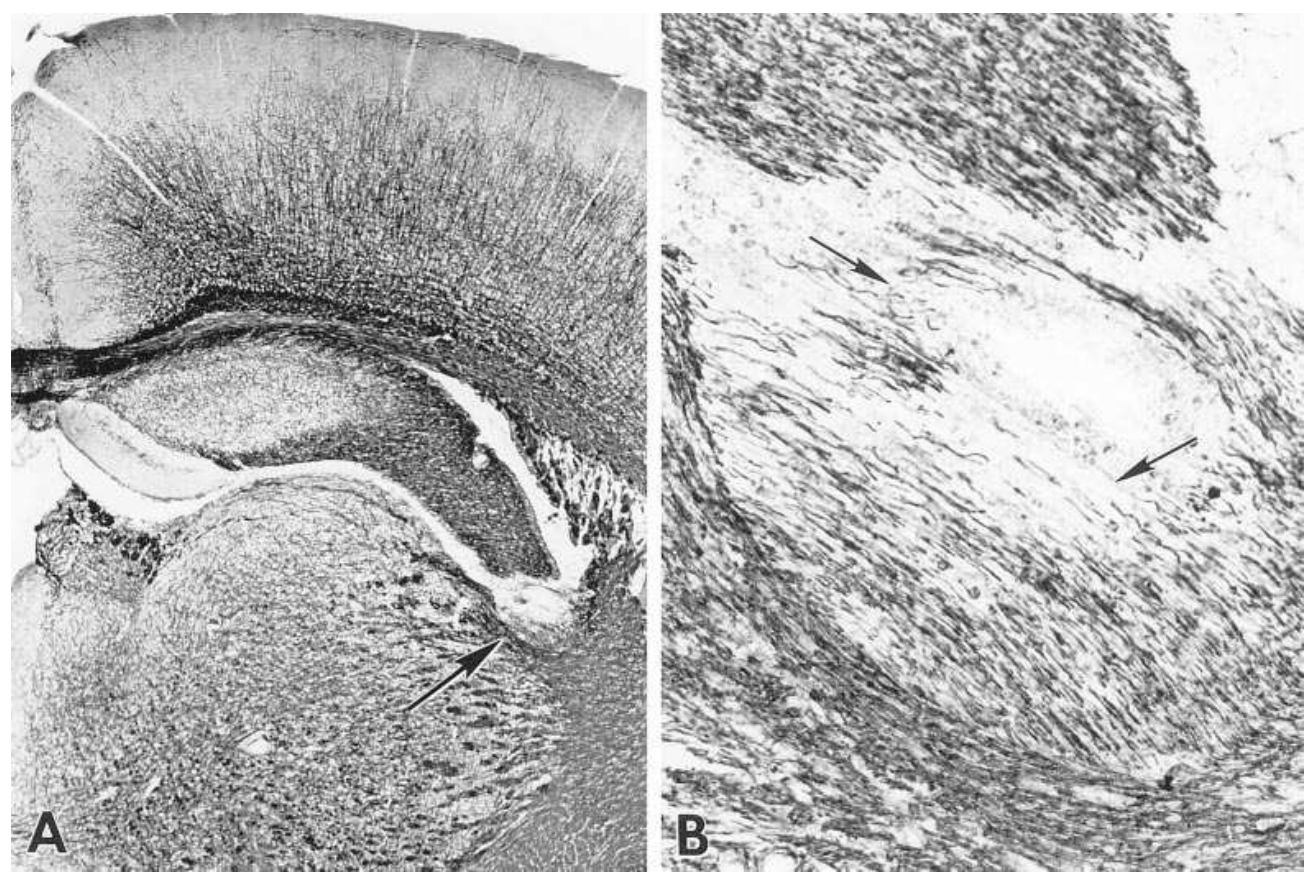

Figure 8. $\mathrm{MBP}-\mathrm{N} 51 / \mathrm{KC}$ tg mice exhibit normal CNS myelination. Coronal sections of mouse brain were stained with antibodies to the myelin protein, PLP as described in Methods. (A) PLP immunostaining in a 19-d tg mouse reveals a generally normal pattern of myelination except for a small area of myelin disruption in an area of periventricular white matter heavily infiltrated by neutrophils (arrow). $\times 24$. (B) Higher magnification of the abnormal area in Fig. $7 A$ shows mechanical displacement of myelinated fibers (arrows) by the infiltrating neutrophils, which are visible as round, refractile cells. $\times 190$. 
In our previous work, oligodendroglia were programmed to express the monocyte chemokine, MCP-1, and migration of monocytes into the CNS perivascular space was observed (53). Leukocyte infiltration of the CNS parenchyma under influence of an individual transgene product, as described in this report, is unprecedented. Expression of the inflammatory cytokine IL-6 from a CNS-specific GFAP promoter resulted in a phenotype of severe neurological impairment and multiple neuropathological alterations, including inflammatory invasion by multiple subtypes of leukocytes (62).

$M B P-N 51 / K C$ transgenic mice are a model of neutrophil recruitment into the CNS. Leukocyte migration into the CNS involves a complex set of interactions between at least three activated cell types: leukocytes, cerebrovascular endothelial cells and resident CNS neuroepithelial cells (2, 6-8, 11, 16, 63). Multiple steps comprise this process of extravasation; these include leukocyte-endothelial interaction, leukocyte cytoskeletal reorganization, release of proteolytic enzymes (by leukocytes and CNS cells), BBB disruption and migration of leukocytes along chemoattractant gradients (64). During inflammation in vivo, mechanistic analysis is complicated by the diverse secreted products produced by multiple cell types.

In MBP-N51/KC tg mice, the chemokine transgene product was generated by oligodendroglia within white matter tracts and orchestrated multiple events required to attract a subpopulation of leukocytes from vasculature to CNS parenchyma (Fig. 3 C). MBP-N51/KC mice therefore represent a potent and unique model for addressing the mechanism of target-selective leukocyte recruitment into the CNS. This system can be used to determine the proximate target cell for CNS $\mathrm{N} 51 / \mathrm{KC}$ action, as endothelial-cell expression of the putative $\mathrm{N} 51 / \mathrm{KC}$ receptor, the IL-8RB murine orthologue, has not been described. The adhesion molecules that are responsible for neutrophil recruitment to CNS tissues can also be investigated. Intercellular adhesion molecule-1 (ICAM-1) was expressed on the endothelial luminal surface of virtually all vessels in CNS tissues of both normal and tg mice, suggesting that its presence may be essential but is not sufficient for neutrophil extravasation Fig. 4, $C$ and $D$ ).

Neutrophil chemokines are likely inflammatory mediators in CNS disorders. Studies of several pathologic conditions of the CNS have tightly linked $\alpha$-chemokine expression to leukocyte invasion. In a stroke model, mRNA of N51/KC and the highly homologous cytokine-induced neutrophil chemoattractant (CINC) were transiently induced in ischemic CNS tissue just prior to neutrophil invasion (46). Similar correlation was obtained using an immunoassay for CINC protein in focal CNS ischemia-reperfusion injury (47). The lag between chemokine expression and neutrophil infiltration suggested resident CNS cells were the source of the chemokine. CNS expression of N51/KC and other chemokines correlated with onset of histologic inflammation and clinical signs in acute EAE, a model for immune-mediated inflammation (65). The functional data presented here strongly support the role of $\alpha$-chemokines in vivo as chemoattractants and inflammatory mediators in the CNS.

Progressive neurologic dysfunction in $\mathrm{MBP}-\mathrm{N} 51 / \mathrm{KC}$ tg mice. Unexpectedly, a high proportion of line 17 MBP-N51/ $\mathrm{KC}$ tg mice developed neurological impairment. Symptoms took the form of a stereotyped progressive syndrome, comprised primarily of truncal ataxia with postural instability, clumsiness and rigidity without weakness. Transgenic mice demonstrated decreased life span, probably because of neurological symptoms that resulted in impaired nutrition and gave rise to a terminal wasting syndrome. Neuropathological examination of affected mice revealed histologic evidence of chronic neutrophil infiltration, advancing microglial and astroglial reaction and apoptosis of neutrophils but no significant damage to neurons, myelin or axons. Based on these findings, one can exclude dysmyelination as a trivial explanation for neurological symptoms in these MBP-N51/KC tg mice $(58,59)$. Purkinje cells, the CNS component most frequently affected in disorders that cause cerebellar dysfunction and ataxia, appeared morphologically normal (data not shown). Interestingly, a syndrome of ataxia and inanition occurred in $\mathrm{tg}$ mice that expressed antisense IL-3 RNA (66). The CNS of these mice was grossly unremarkable. Transgene expression in brains was documented but not assigned a cellular source. IL-3 had been previously shown to have trophic function for central cholinergic neurons, but observations made in the IL-3 antisense mice indicates that $\mathrm{tg}$ manipulations can potentially disclose unanticipated roles of these pleiotropic products (67).

Several potential explanations for the neurological syndrome in these mice can be advanced, based on our data and recent research reports (68). The neurological syndrome seems unlikely to be consequent to acute neuronal toxicity of $\mathrm{N} 51 / \mathrm{KC}$ gene product, as mice were completely asymptomatic at the time of peak chemokine production. It also seems improbable that toxic products of activated neutrophils brought about neural dysfunction in the CNS of MBP-N51/KC tg mice, as evidence of neutrophil degranulation was lacking; furthermore, injection of $\operatorname{tg}$ mice with neutrophil-activating agents such as lipopolysaccharide produced no evident clinical effect.

Microglial and astroglial reaction was the most salient pathological alteration in the CNS of affected tg mice (Figs. 6 and 7). The intensity of glial reaction rose steadily with age, spreading to involve the cortex extensively, in parallel with the increasing incidence of frank neurological symptoms (compare Figs. 6, $B$ and $C$, and 7, $B$ and $C$ ). These observations suggest that the activation of microglia and/or astroglia by neutrophils or chemokine could lead to expression of factors that might impair neural function. Microglial reaction was particularly pronounced, and appeared to be stimulated in part by contact with apoptotic neutrophils, making the microglial cell population an attractive candidate for the mediator of neurological symptoms in MBP-N51/KC $\mathrm{tg}$ mice. In regions of abundant neutrophil infiltration of the parenchyma, $\mathrm{BBB}$ disruption could be documented (Fig. $4 A$ ), indicating that exposure to serum proteins might also be pertinent for neural dysfunction in MBP-N51/KC tg mice, as recently proposed for AIDSdementia complex (69).

Recent reports indicate that the human CNS contains multiple populations of projection neurons that are immunoreactive with antibodies to two chemokine receptors: the IL-8 B receptor and the Duffy antigen receptor for chemokines (DARC) (70). Furthermore, cerebellar membrane preparations bind the melanocyte growth stimulatory activity (MGSA) chemokine with the characteristic affinity of the DARC receptor species (70). These intriguing observations may help to clarify previous reports regarding biological responses to IL-8 by cultured hippocampal neurons (71). Taken in this context, our current findings prompt the speculation that neurological symptoms in MBP-N51/KC tg mice could be explained in part by direct receptor-mediated effects of continuous chemokine 
exposure on CNS neurons, either by chronic agonist action or by receptor desensitization $(11,36,72,73)$. It will be important to distinguish among these various potential mechanisms of neural dysfunction in MBP-N51/KC tg mice, to assist in the design of therapies that safely and effectively modulate CNS chemokine action $(68,74)$.

\section{Acknowledgments}

We are grateful to Robert Lazzarini for the $\mathrm{pM} \beta \mathrm{P}$ vector. We thank Craig Gerard and Carmen Bozic for providing polyclonal antisera to $\mathrm{KC}$ and recombinant $\mathrm{KC}$ for preabsorption studies. Hector MunozRamirez, Bogdan Klinkosz and Alexand de Lahunta provided invaluable help in characterizing the neurological syndrome. We thank Petronio Zalamea for microinjections, Mavis Swerdel for genotyping, Anne Lewin for help with preliminary histological analysis and Caroline Giordano for technical assistance with the transgenic mice. We thank Stephen C. Peiper (University of Louisville) for communicating published results before their appearance.

This research was supported by a fellowship of the National Multiple Sclerosis Society (FG 1079A1/T to M. Tani) and the National Institutes of Health (1RO1-NS32151 to R.M. Ranshohoff).

\section{References}

1. Johansson, B.B. 1990. The physiology of the blood-brain barrier. In Circulating regulatory factors and neuroendocrine function. J.C. Porter, and D. Jezova, editors. Plenum Press, New York. 25-39.

2. Fabry, Z., C. Raine, and M. Hart. 1994. Nervous tissue as an immune compartment: The dialect of the immune response in the CNS. Immunol. Today. 15:218-224.

3. Cserr, H., and P. Knopf. 1992. Cervical lymphatics, the blood-brain-barrier and the immunoreactivity of the brain. Immunol. Today. 13:507-512.

4. Risau, W. 1994. Molecular biology of blood-brain barrier ontogenesis and function. Acta Neurochir. (Suppl.). 60:109-112.

5. Broadwell, R.D. 1993. Endothelial cell biology and the enigma of transcytosis through the blood-brain barrier. In Frontiers in Cerebral Vascular Biology: Transport and Its Regulation. L.R. Drewes, and A.L. Betz, editors. Plenum Press, New York. 137-141.

6. Hickey, W.F. 1991. Migration of hematogenous cells through the bloodbrain barrier and the initiation of CNS inflammation. Brain Pathol. 1:97-105.

7. Springer, T.A. 1994. Traffic signals for lymphocyte recirculation and leukocyte emigration: The multistep paradigm. Cell. 76:301-314.

8. Butcher, E. 1991. Leukocyte-endothelial cell recognition: three (or more) steps to specificity and diversity. Cell. 67:1033-1036.

9. Lindley, I., J. Westwick, and S. Kunkel. 1993. Nomenclature announcement: the chemokines. Immunol. Today. 14:24.

10. Oppenheim, J.J., C. Zachariae, N. Mukaida, and K. Matsushima. 1991. Properties of the novel proinflammatory supergene "intercrine" cytokine family. Annu. Rev. Immunol. 9:617-648.

11. Ben-Baruch, A., D.F. Michiel, and J.J. Oppenheim. 1995. Signals and receptors involved in recruitment of inflammatory cells. J. Biol. Chem. 270: 11703-11706.

12. Glabinski, A.R., M. Tani, S. Aras, M.H. Stoler, V.K. Tuohy, and R.M. Ransohoff. 1995. Regulation and function of central nervous system chemokines. Int. J. Dev. Neurosci. 13:153-165.

13. Miller, M.D., and M.S. Krangel. 1992. Biology and biochemistry of the chemokines, a family of chemotactic and inflammatory cytokines. Crit. Rev. Immunol. 12:17-46.

14. Baggiolini, M., and C.A. Dahinden. 1994. CC chemokines in allergic inflammation. Immunol. Today. 15:127-133.

15. Baggiolini, M., B. Dewald, and B. Moser. 1994. Interleukin-8 and related chemotactic cytokines-CXC and CC chemokines. Adv. Immunol. 55:97179.

16. Tani, M., and R.M. Ransohoff. 1994. Do chemokines mediate inflammatory cell invasion of the central nervous system parenchyma? Brain Pathol. 4: 135-143.

17. Wolpe, S., and A. Cerami. 1989. Macrophage inflammatory proteins 1 and 2: members of a novel superfamily of cytokines. FASEB J. 3:2565-2573.

18. Gomez-Chiari, M., A. Ortiz, D. Seron, E. Gonzalez, and J. Egido. 1993. The intercrine superfamily and renal disease. Kidney Int. 43 (Suppl. 39):S81S85.

19. Gray, P. 1994. The role of chemokines and their receptors in leukocyte activation. In Chemotactic cytokines: targets for therapeutic development. K. Gallagher, editor. IBC, Washington, DC. 118-126.
20. Cochran, B.J., A.C. Reffel, and C.D. Stiles. 1983. Molecular cloning of gene sequences regulated by platelet-derived growth factor. Cell. 33:939-947.

21. Huang, S., J.D. Paulauskis, J.J. Godleski, and L. Kobzik. 1992. Expression of macrophage inflammatory protein-2 and KC mRNA in pulmonary inflammation. Am. J. Pathol. 141:981-988.

22. Oquendo, P., J. Alberta, D. Wen, J.L. Graycar, R. Derynck, annd C.D. Stiles. 1989. The platelet-derived growth factor-inducible KC gene encodes a secretory protein related to platelet alpha-granule proteins. J. Biol. Chem. 264: 4133-4137.

23. Ryseck, R.-P., H. MacDonald-Bravo, M.G. Mattei, and R. Bravo. 1989. Cloning and sequence of a secretory protein induced by growth factors in mouse fibroblasts. Exp. Cell Res. 180:266-275.

24. Heinrich, J.N., E.C. O'Rourke, L. Chen, H. Gray, K.S. Dorfman, and R. Bravo. 1994. Biological activity of the growth factor-induced cytokine N51: structure-function analysis using N51/interleukin-8 chimeric molecules. Mol. Cell. Biol. 14:2849-2861.

25. Bozic, C.R., L.J. Kolakowski, N.P. Gerard, C. Garcia-Rodriguez, A. von Uexkull, C. Guldenband, M.J. Conklyn, R. Breslow, H.J. Showell, and C. Gerard. 1995. Expression and biologic characterization of the murine chemokine KC. J. Immunol. 154:6048-6057.

26. Frevert, C.W., S. Huang, H. Danaee, J.D. Paulauskis, and L. Kobzik. 1995. Functional characterization of the rat chemokine KC and its importance in neutrophil recruitment in a rat model of pulmonary inflammation. J. Immunol. 154:335-344.

27. Lira, S.A., P. Zalamea, J.N. Heinrich, M.E. Fuentes, D. Carrasco, A.C. Lewin, D.S. Barton, S. Durham, and R. Bravo. 1994. Expression of the chemokine $\mathrm{N} 51 / \mathrm{KC}$ in the thymus and epidermis of transgenic mice results in marked infiltration of a single class of inflammatory cells. J. Exp. Med. 180: 2039-2048.

28. Baggiolini, M., and I. Clark-Lewis. 1992. Interleukin-8, a chemotactic and inflammatory cytokine. FEBS Lett. 307:97-101.

29. Feuerstein, G., and R. Rabinovici. 1994. Importance of interleukin-8 and chemokines in organ injury and shock. Crit. Care Med. 22:550-551.

30. Gautam, S., J. Battisto, J.A. Major, D. Armstrong, M. Stoler, and T.A. Hamilton. 1994. Chemokine expression in trinitrochlorobenzene-mediated contact hypersensitivity. J. Leukocyte. Biol. 55:452-460.

31. Kobzik, L., S. Huang, J.D. Paulauskis, and J.J. Godleski. 1993. Particle opsonization and lung macrophage cytokine response. In vitro and in vivo analysis. J. Immunol. 151:2753-2759.

32. Shiratori, Y., H. Takada, Y. Hikiba, K. Okano, Y. Niwa, M. Matsumura, Y. Komatsu, and M. Omata. 1993. Increased release of KC/gro protein, intercrine cytokine family, from hepatocytes of chronically ethanol fed rats. Biochem. Biophys. Res. Commun. 197:319-325.

33. Shiratori, Y., Y. Hikiba, E. Mawet, Y. Niwa, M. Matsumura, N. Kato, S. Shiina, M. Tada, Y. Komatsu, and T. Kawabe. 1994. Modulation of KC/gro protein (interleukin- 8 related protein in rodents): release from hepatocytes by biologically active mediators. Biochem. Biophys. Res. Commun. 203:1398-1403.

34. Sekido, N., N. Mukaida, A. Harada, I. Nakanishi, Y. Watanabe, and K. Matsushima. 1993. Prevention of lung reperfusion injury in rabbits by a monoclonal antibody against interleukin-8. Nature (Lond.). 365:654-657.

35. Heinrich, J.N., and R. Bravo. 1995. The orphan mouse receptor Interleukin (Il)-8R $\beta$ binds N51. J. Biol. Chem. 270:4987-4989.

36. Kelvin, D., D. Michiel, J. Johnston, A. Lloyd, H. Sprenger, J. Oppenheim, and J.-M. Wang. 1993. Chemokines and serpentines: the molecular biology of chemokine receptors. J. Leukocyte Biol. 54:604-612.

37. Lee, J., R. Horuk, G. Rice, G. Bennett, T. Camerato, and W. Wood 1992. Characterization of two high-affinity human interleukin- 8 receptors. $J$. Biol. Chem. 267:16283-16287.

38. Lee, J., G. Cacalano, T. Camerato, K. Toy, M.W. Moore, and W.I Wood. 1995. Chemokine binding and activities mediated by the mouse IL-8 receptor. J. Immunol. 155:2158-2164.

39. Malech, H.L., and J.I. Gallin. 1987. Neutrophils in human diseases. N. Engl. J. Med. 317:687-694.

40. Perry, V.H., and P.-B. Andersson. 1992. The inflammatory response in the CNS. Neuropathol. Appl. Neurobiol. 18:454-459.

41. Suckling, A., J. Kirby, and M. Rumsby. 1981. Characterization by acid alpha-naphthyl acetate esterase staining of the spinal cord cellular infiltrate in the acute and relapse phases of chronic relapsing experimental allergic encephalomyelitis. In Noble Bodman Symposium on Immunological Aspects of Acute and Chronic Nervous Disorders. Vol. 59. P. Behan, V. ter Meulen, and F. Rose, editors. Elsevier, London, UK. 317-323.

42. Herndon, R., and R. Brumback. 1989. The Cerebrospinal Fluid. Kluwer Academic Publishers, Boston, MA.

43. Mathews, W., A. Compston, I. Allen, and C. Martyn. 1991. McAlpine's Multiple Sclerosis. Churchill Livingstone, Edinburgh.

44. Ransohoff, R., A. Glabinski, and M. Tani. 1996. Chemokines in immune-mediated inflammation of the central nervous system. Cytokine Growth Factor Reviews. In press.

45. Glabinski, A.R., M. Tani, V. Balasingam, V.W. Yong, and R.M. Ransohoff. 1996. Chemokine monocyte chemoattractant protein-1 (MCP-1) is expressed by astrocytes after mechanical injury to the brain. J. Immunol. 156: 4363-4368. 
46. Liu, T., P.R. Young, P.C. McDonnell, R.F. White, F.C. Barone, and G.Z. Feuerstein. 1993. Cytokine-induced neutrophil chemoattractant mRNA expressed in cerebral ischemia. Neurosci. Lett. 164:125-128.

47. Kim, J.S., S.C. Gautam, M. Chopp, C. Zaloga, M.L. Jones, P.A. Ward, and K.M.A. Welch. 1995. Expression of monocyte chemoattractant protein-1 and macrophage inflammatory protein-1 after focal cerebral ischemia in the rat. J. Neuroimmunol. 56:127-134.

48. Saukkonen, K., S. Sande, C. Cioffe, S. Wolpe, B. Sherry, A. Cerami, and E. Tuomanen. 1990. The role of cytokines in the generation of inflammation and tissue damage in experimental gram-positive meningitis. J. Exp. Med. 171: 439-448.

49. Seebach, J., D. Bartholdi, K. Frei, K. Spanaus, E. Ferrero, U. Widmer, S. Isennann, R. Streiter, M. Schwab, H. Pfister, and A. Fontana. 1995. Experimental Listeria meningoencephalitis macrophage inflammatory protein- $1 \alpha$ and -2 are produced intrathecally and mediate chemotactic activity in cerebrospinal fluid of infected mice. J. Immunol. 155:4367-4375.

50. Yamasaki, Y., Y. Matsuo, N. Matsuura, H. Onodera, Y. Itoyama, and K. Kogure. 1995. Transient increase of cytokine-induced neutrophil chemoattractant, a member of the interleukin- 8 family, in ischemic brain areas after focal ischemia in rats. Stroke. 26:318-323.

51. Tani, M., A.R. Glabinski, V.K. Tuohy, M.H. Stoler, M.L. Estes, and R.M. Ransohoff. 1996. In situ hybridization analysis of glial fibrillary acidic protein mRNA reveals evidence of biphasic astrocyte activation during acute experimental autoimmune encephalomyelitis. Am. J. Pathol. 148:889-896.

52. Karpus, W.J., N.W. Lukacs, B.L. McRae, R.M. Strieter, S.L. Kunkel, and S.D. Miller. 1995. An important role for the chemokine macrophage inflammatory protein- $1 \alpha$ in the pathogenesis of the T cell-mediated autoimmune disease, experimental autoimmune encephalomyelitis. J. Immunol. 155:50035010 .

53. Fuentes, M., S. Durham, M. Swerdel, A. Lewin, D. Barton, J. Megill, R. Bravo, and S.A. Lira. 1995. Controlled recruitment of monocytes/macrophages to specific organs via transgenic expression of MCP-1. J. Immunol. 155:5769-5776.

54. Andersson, P.B., V.H. Perry, and S. Gordon. 1992. Intracerebral injection of proinflammatory cytokines or leukocyte chemotaxins induces minimal myelonomocytic cell recruitment to the parenchyma of the central nervous system. J. Exp. Med. 176:255-259.

55. Gow, A., V. Friedrich, and R. Lazzarini. 1992. Myelin basic protein gene contains separate enhancers for oligodendrocyte and schwann cell expression. J. Cell Biol. 119:605-616.

56. Eng, L.F., J.J. Vanderhaeghen, A. Bignami, and B. Gerstl. 1971. An acidic protein isolated from fibrous astrocytes. Brain Research. 28:351-354.

57. Eng, L.F. 1985. Glial fibrillary acidic protein (GFAP): the major protein of glial intermediate filaments in differentiated astrocytes. J. Neuroimmunol. 8: 203-214.

58. Turnley, A., G. Morahan, H. Okano, O. Bernard, K. Mikoshiba, J. Allison, P. Bartlett, and J. Miller. 1991. Dysmyelination in transgenic mice resulting from expression of class I histocompatibility molecules in oligodendrocytes.
Nature (Lond.). 353:566-569.

59. Power, C., P.-A. Kong, and B. Trapp. 1996. MHC class I expression in oligodendrocytes induces hypomyelination in transgenic mice. J. Neurosci. Res. 44:165-173.

60. Metzner, B., M. Barbisch, F. Parlow, E. Kownatzki, I. Schraufstatter, and J. Norgauer. 1995. Interleukin-8 and GRO $\alpha$ prime human neutrophils for superoxide anion production and induce up-regulation of $\mathrm{N}$-formyl peptide receptors. J. Invest. Dermatol. 104:789-791.

61. Kalmar, J.R., and T.E. VanDyke. 1994. Effect of bacterial products on neutrophil chemotaxis. Methods Enzymol. 236:58-87.

62. Campbell, I.L., C.R. Abraham, E. Masliah, P. Kemper, J.D. Inglis, M.B. Oldstone, and L. Mucke. 1993. Neurologic disease induced in transgenic mice by cerebral overexpression of interleukin 6. Proc. Natl. Acad. Sci. USA. 90:10061-10065.

63. Hickey, W.F., B.L. Hsu, and H. Kimura. 1991. T-lymphocyte entry into the central nervous system. J. Neurosci. Res. 28:254-260.

64. Romanic, A.M., and J.A. Madri. 1994. Extracellular matrix-degrading proteinases in the nervous system. Brain Pathol. 4:145-156.

65. Ransohoff, R.M., T.A. Hamilton, M. Tani, M.H. Stoler, H.E. Shick, J.A. Major, M.L. Estes, D.M. Thomas, and V.K. Tuohy. 1993. Astrocyte expression of mRNA encoding cytokines IP-10 and JE/MCP-1 in experimental autoimmune encephalomyelitis. FASEB J. 7:592-600.

66. Cockayne, D.A., D.M. Bodine, A. Cline, A.W. Nienhuis, and C.E. Dunbar. 1994. Transgenic mice expressing antisense interleukin-3 RNA develop a B-cell lymphoproliferative syndrome or neurologic dysfunction. Blood. 84: 2699-2710.

67. Kamegai, M., K. Niijima, T. Kunishita, M. Nishizawa, M. Ogawa, M. Ar aki, A. Ueki, Y. Konishi, and T. Tabira. 1990. Interleukin 3 as a trophic factor for central cholinergic neurons in vitro and in vivo. Neuron. 2:429-439.

68. Kunkel, S., R. Strieter, I. Lindley, and J. Westwick. 1995. Chemokines: new ligands, receptors and activities. Immunol. Today. 12:559-561.

69. Power, C., P. Kong, T. Crawford, S. Wesselingh, J. McArthur, J. Glass, and B. Trapp. 1993. Cerebral white-matter changes in AIDS dementia: alterations of the blood-brain barrier. Ann. Neurol. 34:339-350.

70. Horuk, R., A. Martin, Z.-X. Wang, T. Hadley, J. Hesselgesser, Z.-h. Lu, and S.C. Peiper. 1995. Chemokine receptors are expressed in the central nervous system. Ninth International Congress of Immunology. 9:107 (Abstr.)

71. Araujo, D.M., and C.W. Cotman. 1993. Trophic effects of interleukin-4 -7 and -8 on hippocampal neuronal cultures: potential involvement of glialderived factors. Brain Res. 600:49-55.

72. Horuk, R. 1994. Molecular properties of the chemokine receptor family. Trends Pharmacol Sci. 15:159-165.

73. Murphy, P. 1994. The molecular biology of leukocyte chemattractant receptors. Annu. Rev. Immunol. 12:593-633.

74. Ransohoff, R.M., and L. Bo. 1996. Cytokines in CNS Inflammation. In Cytokines in the CNS. R.M. Ransohoff, and E.N. Benveniste, editors. CRC Press, Boca Raton, FL. 221-239. 